\title{
RESENHA: “ADAM SMITH EM PEQUIM: ORIGENS E FUNDAMENTOS DO SÉCULO XXI", DE GIOVANNI ARRIGHI (BOITEMPO EDITORIAL, 2008)
}

\author{
Pedro Antonio Vieira'
}

Numa rápida pesquisa na internet encontramos dezenas de livros editados no Brasil, os quais, sob os mais variados aspectos e com diferentes graus de profundidade, têm a China como tema. O horóscopo chinês, relatos de viagem, de experiências de chineses que agora vivem no ocidente, guia para negócios, as reformas de Den Xiao Ping, o pensamento e a culinária chinesas, enfim, há livros para todos os gostos e exigências intelectuais. Em maior ou menor grau, é possível que todos eles contribuam para um melhor conhecimento do país que certamente continuará a chamar nossa atenção por muito tempo, como sugere o sub-título da obra que agora nos ocupa.

Entre os livros recentemente publicados sobre a China, merece destaque Adam Smith em Pequim, de Giovanni Arrighi, tanto pelo tema em si quanto pelo método de abordagem. Nesta obra, Arrighi dedica-se a explicar teórica e historicamente a ascensão da China à posição de locomotiva da economia mundial, bem como as implicações para toda a humanidade, da perda desta posição pelo Ocidente e, em particular, pelos Estados Unidos.

Como se vê, trata-se de uma obra ambiciosa. Mas devemos ter em conta que Giovanni Arrighi não é um aventureiro intelectual, alguém que procura espaço no mercado editorial ofertando uma mercadoria da moda, neste caso a China. Ao contrário, é um cientista social que vem há décadas desenvolvendo - junto com pesquisadores de várias partes do mundo - um programa de pesquisa consistente sobre o capitalismo contemporâneo e cujos resultados vieram à luz através de seus três livros anteriores $(O$ Longo Século XX, Ed. Unesp, 1996; A ilusão do desenvolvimento, Vozes, $1996 \mathrm{e}$ Caos e Governabilidade, Contraponto/Ed.UFRJ, 2001).

Professor do Departamento de Economia da UFSC e Coordenador do Grupo de Pesquisa em Economia Política dos Sistemas-Mundo. E-mail: pavieira@cse.ufsc.br. Uma versão deste texto foi publicada no Caderno Cultura na edição de 8/8/2009 do jornal Diário Catarinense. 
Tendo como matriz intelectual Karl Marx, Max Weber, Joseph Schumpeter e Fernand Braudel, e revelando uma extraordinária capacidade de resignificar e vislumbrar novas aplicações aos conceitos de outros autores, em $O$ Longo Século $X X$ Giovanni Arrighi desenvolveu sua própria concepção do desenvolvimento do capitalismo histórico do século XVI até o início dos anos 90. Como ele mesmo disse, subindo nas costas de Braudel, pôde ver que sistema capitalista mundial passou por ciclos, nos quais um estado e seus capitalistas exerciam a hegemonia, ou seja, detinham a capacidade política, militar e econômica necessárias para estabelecer a ordem política no sistema interestatal e assim assegurar as condições para o prosseguimento da acumulação de capital e para a conseqüente expansão do sistema mundial. Esta capacidade é o que Arrighi entende por hegemonia, que, portanto, se diferencia da pura dominação. O dinamismo da acumulação e as disputas entre os estados fazem com que esta hegemonia tenha sido sempre temporária. Holanda, Inglaterra e Estados Unidos foram as nações que exerceram a hegemonia, sendo que desde a década de 1970 a hegemonia estadunidense, iniciada na década de 1930, começou a declinar, ainda que conservando a supremacia milita. Concomitantemente, o Leste Asiático, puxado pelo Japão, estava se transformando em centro de produção de riqueza, mas Arrighi não via a nação nipônica com todos os requisitos para substituir os EUA como potência hegemônica, principalmente porque estes últimos continuaram com a supremacia militar e monetária. A questão da transição hegemônica, que tinha sido recorrente na história do capitalismo, apresentava-se indefinida. Neste debate, a China não era mencionada.

Em Caos e Governabilidade, publicado em 1999, a China já é mencionada com muito mais freqüência, porque seu crescimento econômico mantinha na Ásia Oriental a proeminência econômica mundial. Certos analistas estadunidenses viam este crescimento como "o acontecimento mais preocupante da era pós-Guerra Fria" e advertiam que não se podia ignorar que a China representava uma ameaça militar para os EUA e para o mundo Ocidental. Para entender as razões desta percepção precisamos saber que as transições hegemônicas sempre aconteceram por meio de grandes convulsões sociais e de conflitos armados entre as potências rivais, como foi o caso das guerras de 1914 e 1939, ao fim das quais a hegemonia passou da Grã-Bretanha para os EUA. Os conflitos são produzidos não apenas porque 
RESENHA: ADAM SMITH EM PEQUIM: Origens e fundamentos do Século XXI, de Giovanni Arrighi (Boitempo Editorial, 2008)

uma ou mais nações decidem empregar a força para conquistar a hegemonia, como foi o caso da Alemanha no século passado, mas também porque a nação hegemônica resiste a ceder seu posto, como parecer ser o caso dos EUA atualmente. Se este já é um bom motivo para o tema geral de Adam Smith em Pequim seja do interesse do assim chamado cidadão comum, o ressurgimento da China significa mudanças ainda mais profundas na história mundial dos últimos 500 anos: em caso de confirmar-se a liderança da Ásia Oriental com a China à frente, pela primeira vez nos últimos cinco séculos, o comando do sistema mundial estaria se deslocando do Ocidente para o Oriente.

Em "Adam Smith em Pequim: Origens e fundamentos do Século XXI", Giovanni Arrighi busca uma explicação teórica e histórica para duas questões absolutamente atuais e interligadas: o ressurgimento econômico e político da Ásia Oriental, que nesta segunda etapa (a primeira foi liderada pelo Japão) tem a China como centro dinâmico, e a perda, pelos EUA, da posição de potencia hegemônica mundial.

O livro está organizado em quatro partes, cada uma com três capítulos. Nos três primeiros da primeira parte (Adam Smith e a nova época asiática), talvez os mais inovadores, Arrighi parte das conflitantes e também insuficientes interpretações da ascensão chinesa, argumenta que elas decorrem de um inadequado quadro conceitual e propõe que para esta finalidade, a teoria do desenvolvimento de Adam Smith é mais útil que a de Karl Marx e de Joseph Schumpeter. Isso porque o notável desenvolvimento econômico experimentado pela China nos séculos XVI e XVIII foi baseado no mercado não capitalista. Este processo se interrompeu justamente quando a Europa, mais precisamente a Grã-Bretanha, onde também havia se desenvolvido uma economia de mercado, entrava numa rota de desenvolvimento tecnológico e econômico que permitiu a esta região do globo acumular riqueza e poderio militar suficientes para submeter a Ásia Oriental nas primeiras décadas do século XIX. Enfim, a Grã-Bretanha e o Ocidente inventaram a acumulação incessante de capital, ou, seja, a via capitalista de desenvolvimento baseada no mercado.

A diferença entre os dois caminhos é a relação entre os capitalistas e o estado. Na Europa, o estado foi maleável aos interesses capitalistas, o que não aconteceu na Ásia Oriental e não porque lá não houvesse estado e capitalistas. A união entre estado e capitalismo, que proporcionou a acumulação interminável de capital no Ocidente, é o que caracteriza como 
capitalista esta via de desenvolvimento. Ora, é da natureza do estado a luta permanente com outros estados, o que leva à necessidade de exércitos e de armas. Os recursos financeiros necessários para financiar as tropas e as armas, como também estas últimas, são fornecidos pelos capitalistas. Arrighi chega, então, à fonte da riqueza e do poder dos estados ocidentais e do correspondente enfraquecimento do resto do mundo: a sinergia entre capitalismo, industrialismo e militarismo.

Por outro lado, apesar de ser tão baseado no mercado quanto o europeu, o caminho de desenvolvimento da Ásia Oriental não "era portador da dinâmica capitalista" porque nesta região os capitalistas não puderam colocar o estado a seu serviço (criando as condições institucionais e políticas para a acumulação interminável) e não porque não houvesse chineses capitalistas.

Na segunda parte (Rastreamento da turbulência global), dois capítulos (4 e 5) são dedicados a um debate talvez demasiadamente detalhado com Robert Brenner sobre a evolução da economia mundial nas décadas de 1970 a 1990. No capítulo seis, Arrighi apresenta sua própria interpretação desta evolução, que não pode ser entendida fora do quadro mais amplo de declínio e tentativa (infrutífera) de recuperação da hegemonia dos EUA, tema de que se ocuparão os três capítulos da terceira parte (A hegemonia desvendada). Neles, embora recuperando argumentos já expostos em outras obras, Arrighi dá destaque à relação entre acumulação e espaço e sustenta, num capítulo sugestivamente intitulado $O$ estado Mundial que nunca existiu, que fracassou a última tentativa dos EUA voltarem à posição de prestigio e poder de que desfrutaram entre 1946 e 1973, o que, inclusive, facilitou a ascensão da China.

Assim como nos três capítulos iniciais, os capítulos 10 a 12, da última parte (Linhagens da era asiática) voltam-se para China. Primeiro, apresentando as três principais posições dos teóricos das relações internacionais estadunidenses a respeito da relação EUA-China e, depois, fazendo uma esclarecedora abordagem histórico-teórica da economia de mercado na China e no Ocidente. O Capítulo 12 rastreia até a revolução comunista de 1949 as causas do atual sucesso chinês e termina apontando, um tanto apressadamente, as contradições deste sucesso (o aumento da desigualdade e a proliferação das lutas sociais).

No Epílogo o autor pisa o solo movediço da história presente para garimpar evidências de que, sob a liderança da China, estaria em construção 
RESENHA: ADAM SMITH EM PEQUIM: Origens e fundamentos do Século XXI, de Giovanni Arrighi (Boitempo Editorial, 2008)

uma nova ordem internacional mais favorável aos povos do hemisfério sul e por extensão, a toda a humanidade. Mas esta civilização mundial menos desigual somente será possível se, na China, a longa tradição do desenvolvimento baseado no mercado e centrado em si mesmo, e de governo com a participação das massas, não for abandonada em favor de um desenvolvimento propriamente capitalista. $\mathrm{O}$ fracasso neste caminho poderia transformar a China num "epicentro de caos social e político", estimulando as potências ocidentais a restabelecerem novamente seu domínio sobre o mundo.

O fato de Arrighi fazer previsões otimistas sobre as possibilidades de a China oferecer ao mundo uma via de desenvolvimento não capitalista, e aos países do Sul Global uma oportunidade de se inserirem de maneira menos desigual numa nova ordem mundial, em nada diminui a relevância e a consistência da pesquisa teórica (principalmente de Adam Smith) e histórica sobre a trajetória chinesa. Dissemos que são otimistas porque é inegável na China o avanço da lógica da acumulação interminável de capital e porque, não há evidências históricas de que seja possível moderar ou submeter esta lógica a um controle social. Por outro lado, e é isto que inspira o otimismo de Arrighi, como se trata de uma sociedade e de um estado com uma longa história de práticas econômicas, políticas e sociais não capitalistas, algo novo pode surgir.

Particularmente relevante (embora discutível, diriam os marxistas) para todos os críticos do capitalismo e defensores de uma sociedade socialista, é a demonstração teórica (agora com base em Smith e não em Braudel) e histórica (com o caso da China) de que o desenvolvimento com base no mercado pode não ser necessariamente capitalista, quer dizer, dominado por aquele tipo de agente econômico que busca, mesmo contra os interesses da sociedade, a acumulação interminável de capital.

Enfim, embora deixando de lado tanto o arcabouço conceitual quanto a problemática de obras anteriores (ou talvez por isto mesmo), em Adam Smith em Pequim Giovanni Arrighi nos brinda com mais uma demonstração de como os cientistas sociais podem oferecer alguma luz para os dilemas do nosso tempo. Para tanto, não devem fugir das grandes questões que afligem a humanidade e sim, enfrentá-las com o método científico adequado, que a nosso ver é aquele que, para revelar a lógica do objeto pesquisado, combina teoria e história e privilegia a comparação inter-temporal (história como dialética das durações) e inter-espacial (qual a extensão espacial do objeto?) 
derrubando, ao mesmo tempo, as barreiras entre as disciplinas (economia, política, antropologia, sociologia, geografia, história).

Por tudo isto, Adam Smith em Pequim candidata-se a ser uma leitura obrigatória para quem quiser ir fundo no estudo teórico e histórico daquela que pode ser a grande questão geopolítica do século XXI: a ascensão da China (e do Oriente em geral) como potencia mundial em detrimento dos EUA e do mundo Ocidental, tese que André Gunder Frank, a quem Arrighi dedica seu livro, defendeu em ReOrient: global economy in the Asian Age, seu último livro, publicado em 1998. 